\title{
Strategic Capacity Management With Modular Manufacturing And Outsourcing: A Case Study
}

Ignacio Garcia, (Email: igarcia@iquest.net), Penn State University, Erie Ray Venkataraman, (Email: rrv2@psu.edu), Penn State University, Erie

\begin{abstract}
This paper proposes that downsizing an industrial manufacturer's capacity is a cost-effective strategy to reduce the cost of conversion while ensuring that adequate capacity is available to meet its business strategy requirements. A case study of a U.S. manufacturer of motors and other mechanical drive systems illustrates a proposed reduction in capacity that utilizes the development and implementation of a cost model to determine the best alternatives for a company whose capacity is not synchronized with its business strategy. The cost model for each alternative is investigated and compared against the 'Do nothing' alternative, using net present value and cash flow analysis to build a case for the most effective course of action. The findings show the benefits of merging manufacturing by separating people, nonpeople, and fixed costs by facility, product line and product. In addition, the paper also illustrates the benefits of modular manufacturing and outsourcing as a way to further improve costs after the reduction of capacity.
\end{abstract}

\section{INTRODUCTION}

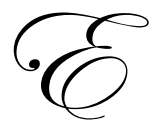

conomic, technological and political factors are a few of the diverse external conditions that can influence companies' decisions to open, close or modify their manufacturing locations and facilities. These factors change over time but especially so in environments of growing global competition, where the development of a capacity and facilities strategy is essential to any manufacturing enterprise (Butler, 1990). In order to develop a capacity and facility strategy for a particular company, it is first necessary to understand how each factor affects their strategic capacity management and impacts market growth, product obsolescence, technology changes and conflicts with the environment. A lack of understanding of these issues can cause a disconnect between the company's capacity and business strategies (Skinner, 1969).

Disconnected strategy drives organizations to make investments in individual projects in relative isolation from their overall long-term strategy. This makes it difficult for companies to identify optimum facility investments that, in turn, can lead to heavy cost structures (Reeve, 2001, Marucheck \& McClelland, 1992). In addition, other studies indicate that many companies also ignore the signals of market demand, building their capacity above the potential of the market. This results in excess capacity and the duplication of overhead costs thereby reducing profitability (Silva, 1994). In order to ensure profitability, it is necessary for companies to review capacity management and capacity utilization in their operations and engage in a planning process that can correct the imbalance. Successful capacity management requires three levels of planning: strategic, tactical and operational (Marucheck \& McClelland, 1992). Strategic planning defines the vision and mission for the company and its long-term goals. Tactical planning involves creating the methods to carry out the company's mission. Operational planning deals with the nuts and bolts of who does what, the implementation plan and so forth. All three elements of planning are critical in developing a revised capacity and facility strategy.

Along with successful capacity management, a company needs to evaluate its capacity utilization. Attention to capacity utilization can help increase a company's profitability. This activity needs to take place in addition to classical operative measures such as turns, cycle time, quality, waste, delivery, market share and growth in sales, (Marucheck \& McClelland, 1992). The most successful methods a company can use to improve capacity management and utilization are 
modular manufacturing and outsourcing. A modular system allows companies to shift design, engineering and lower-tier supply-chain management duties to their largest suppliers. Modules become not only assemblages of parts but also systems that can be "optimized" or looked at in their entirety for ways of improving performance and reducing cost and complexity. The modules referred to in the concept of modular manufacturing are sub-assemblies that are built up and supplied by outside contractors to an assembly plan. The plant puts them together as part of the final assembly. Among the advantages this method offers to the assembly plant is that it creates fewer components to assemble, uses less manpower and generates less inventory.

A logical connection to modular manufacturing is the concept of outsourcing. Outsourcing is the act of moving some of the company's internal activities and decision responsibility to outside providers. The concept of outsourcing is a key business function that can be leveraged by small businesses. Companies want to outsource to reduce or control costs, improve the company's focus on its core competency, get access to world-class capabilities, share the risks of its business and ensure the company operates in a lean environment. The legitimacy and perceived value of outsourcing is also changing. Ten years ago, companies were using temporary employees to fix problems and deal with cycles of the market. Today, outsourcing has moved closer to the core corporate functions and has evolved into an accepted business model. As the business community has become more and more comfortable with the concept of outsourcing, the level of complexity and sophistication of outsourced functions has reached new levels. Outsourcing is now being viewed as a cost-effective way to take advantage of new ideas, new solutions and best-in-class processes and technology. Although outsourcing has definite benefits to manufacturers, it is creating increasing concern among workers and unions.

Implementing modular systems and outsourcing offer an effective way to gain competitive advantage, lower costs and increase efficiency. They are tools that can be used in the creation of a more balanced and effectively managed manufacturing capacity. Exploring alternatives such as these is important as they are critical to the very survival of many contemporary manufacturers.

\section{PAST RESEARCH}

From the perspective of manufacturing strategy, efficient capacity management is concerned with capacity expansion and reduction in order to respond to long-term changes in demand levels. Strategic capacity management is essential as it has a significant impact on the competitive performance dimensions of cost, delivery speed, dependability and flexibility (Olhager et.al., 2001). Past research has identified that the development of a connected facilities strategy and the development of a production capacity are essential to any manufacturing company that wants to reduce costs (Butler, 1990). The capacity strategy and the business strategy need to be connected to prevent unnecessary investments to repair or replace assets when a duplication of capacity exists (Skinner, 1969, Reeve, 2001). Previous studies have also demonstrated that effectively managing manufacturing capacity is of growing importance to all industries (Orr, 1999). This is especially true when competition is reducing costs, cutting capital spending and reducing margins to compete in the market.

Past research has also detected that a weak connection between strategic capacity management and the business plan can result in disconnecting the strategic and tactical phases of planning. Capacity management needs to be reviewed at the three planning levels: The strategic, the tactical and the operational. (Silva, 1994, Marucheck \& McClelland,1992). Current studies also indicate that companies ignore the signals of the market demand, building capacity above the potential of the market. This causes an excess of capacity and the duplication of overhead costs, (Silva, 1994). "When the bottleneck is above the level of highest demand a high level control needs to be exercised to avoid capacity duplication and stop spending in capital funds" (Reeve, 2001).

This paper builds on previous research by Stuart Orr (1999) in which Orr identified that a drop in demand will cause higher inventories, and an excess of capacity, staffing and investment levels. The lack of communication between departments such as marketing and production limits the effectiveness of capacity management. This study supports the importance of the previous concepts and expands on them by recommending the addition of a cost model to analyze the benefits of a reduction of capacity in order to improve costs. In addition, this study recommends the use of modular manufacturing and outsourcing concepts to improve costs and to prevent unnecessary capital investments. Modular manufacturing and outsourcing involves shifting work to factories with lower labor costs thereby reducing the size of the existing labor force (Welch, 2001). As a result, unions are including this issue in their negotiations to obtain better pay or 
increase protection against companies implementing the modular approach (Velocci, 2002). However, outsourcing has also created a motivation for employees to try and improve their performance and prevent the elimination of jobs.This shift helps the company focus on core activities, create flexibility, obtain expertise, skills and technology, reduce risk, working capital, and investment, and achieve lower cost structure (Strozniak, 2001).

\section{RESEARCH ENVIRONMENT}

An established U.S. company that manufactures motors and other mechanical drive systems served as a reference system for this study. Aquanaut is a manufacturer of boat motors and has been the leader in that market for the past 30 years. However, market fluctuations, customer product vertical integration and the product becoming a commodity has forced the company to review its approach to the market. It decided to become the lowest cost producer in the market. The company has two plants currently producing motors with almost 1,700 employees. The first is the Shark Plant and the second plant the Dolphin Plant. The dual plant strategy started in the early 1980's, following a 60-day strike at the Shark Plant. The two plants make motors for the same market but after a few years the Dolphin Plant adopted a new design to cover a specific niche of the market. Both motors are used in boats with different capacities and applications. The long-term existence of the Shark Plant has created a heavy structure to support the operation, causing an increased product cost. In contrast, the Dolphin Plant has remained small.

Market share for aquatic motors has been declining due to imports and customers developing their own motors over the past three years. The market is small and there are many motor suppliers offering the same type of product with additional customer rebates. The aquatic motor market is erratic and very cyclical, causing problems with customer forecasts. As a result, changes to plan are very frequent. The projected 2003 demand will be reduced by 28 percent in comparison to 1995 figures.

In terms of its physical production layout, Aquanaut has three manufacturing lines: S1 \& S2 at the Shark Plant, and the D1 at the Dolphin Plant. Line S1 is flexible but old in technology. S2 is new but limited in capacity. D1 line is flexible and new in technology. The plants have increased their capacity over time at infrequent intervals using methods that created an excess in capacity. Also, It is evident that each plant added capacity without engaging in central coordination to avoid duplication. The company's chosen initiative, to become the lowest cost motor producer in the boat market, will require an overall improvement in different categories of the product. However, the focus of this study will be its project to reduce capacity duplication and therefore reduce the cost of conversion.

\section{PROBLEM DEFINITION}

Aquanaut's problem is the high cost of conversion for the boat motors that is produces, created by an excess of capacity that exceeds historic and forecasted demand by more than three times. External competition and weak market demand cut production volumes by almost thirty percent over the past few years. Lack of coordinated approval and implementation of capital projects led to investments to expand capacity in separate locations during that time. The Shark plant has two products, A \& B, and two assembly lines, S1 \& S2, while the Dolphin plant has only one product, C, and one assembly line, D1. The Shark plant will produce more than 250,000 units (approximately 12,000 units for product S1) will be produced in 2003 year but only 115,000 will be produced in the Dolphin Plant. Forecasted demand for the next four years shows demand peaks as higher as $350,000 \mathrm{~B}$ units and 120,000 C units. The B product is becoming obsolete through decreasing demand. Capacity has increased by twenty percent over the years. The maximum annual capacity for each line is S1 with 670,000 units, S2 with 278,000 units and D1 with 764,000 units. The overall Aquanaut's Capacity Utilization Rate has reduced from 47 percent in 1995 to 26 percent in 2002. The reduction is caused by the obsolescence of product A and a decline in customer demand for product $\mathrm{C}$. Table I provides the demand information on the three products and the total capacity and Table II provides information capacity utilization rate for Aquanaut Motors for the years 1995 to 2003.

The excess of capacity is causing higher costs of conversion. This is caused mainly by the duplication of resources to operate two separate facilities, an excess of assets and their depreciation to produce similar products and the existence of a support infrastructure to be ready to meet demand of obsolete products. The Shark plant will spend 79 million for operations and the Dolphin plant will spend only 27 million. The average people cost for the Shark plant is higher than that of the Dolphin plant. While the non-people and fixed costs are similar between the two plants, 
total unit cost for the Dolphin Plant is significantly less than the average total unit cost for the Shark plant. Table III provides the cost information for the two plants.

Table I

Demand Information For Aquanaut Motors

\begin{tabular}{|l|c|c|c|c|c|c|c|c|c|}
\hline & $\mathbf{1 9 9 5}$ & $\mathbf{1 9 9 6}$ & $\mathbf{1 9 9 7}$ & $\mathbf{1 9 9 8}$ & $\mathbf{1 9 9 9}$ & $\mathbf{2 0 0 0}$ & $\mathbf{2 0 0 1}$ & $\mathbf{2 0 0 2}$ & $\mathbf{2 0 0 3}$ \\
\hline Product A & 434000 & 280000 & 322000 & 392000 & 336000 & 329000 & 103432 & 77000 & 11760 \\
\hline Product B & 0 & 0 & 0 & 0 & 0 & 28000 & 49000 & 189000 & 244000 \\
\hline Product C & 210000 & 280000 & 336000 & 336000 & 336000 & 252000 & 168000 & 168000 & 115000 \\
\hline Total & 644000 & 560000 & 658000 & 728000 & 672000 & 609000 & 320432 & 434000 & 370760 \\
\hline
\end{tabular}

Table II

Capacity Utilization Rate And Total Capacity Information For Aquanaut Motors

\begin{tabular}{|l|c|c|c|c|c|r|r|r|r|}
\hline & $\mathbf{1 9 9 5}$ & $\mathbf{1 9 9 6}$ & $\mathbf{1 9 9 7}$ & $\mathbf{1 9 9 8}$ & $\mathbf{1 9 9 9}$ & $\mathbf{2 0 0 0}$ & $\mathbf{2 0 0 1}$ & $\mathbf{2 0 0 2}$ & $\mathbf{2 0 0 3}$ \\
\hline Product A & $66 \%$ & $42 \%$ & $49 \%$ & $59 \%$ & $51 \%$ & $50 \%$ & $16 \%$ & $12 \%$ & $2 \%$ \\
\hline Product B & & & & & & $20 \%$ & $35 \%$ & $68 \%$ & $88 \%$ \\
\hline Product C & $27 \%$ & $37 \%$ & $44 \%$ & $44 \%$ & $44 \%$ & $33 \%$ & $22 \%$ & $22 \%$ & $15 \%$ \\
\hline Overall capacity utilization rate & $47 \%$ & $41 \%$ & $48 \%$ & $53 \%$ & $49 \%$ & $40 \%$ & $21 \%$ & $26 \%$ & $23 \%$ \\
\hline Total Capacity (in 000's of units) & 1378 & 1378 & 1378 & 1378 & 1378 & 1512 & 1512 & 1646 & 1646 \\
\hline
\end{tabular}

Table III

Per Unit Cost Information In Dollars For The Two Plants

\begin{tabular}{|l|c|c|c|}
\hline Plant & Shark & Shark & Dolphin \\
\hline Product & A & B & C \\
\hline People Costs & 235.70 & 327.38 & 155.65 \\
\hline Non-people costs & 54.10 & 68.03 & 63.48 \\
\hline Other costs & 11.89 & 76.53 & 18.26 \\
\hline Total manufacturing cost & 301.68 & 471.94 & 237.39 \\
\hline
\end{tabular}

One way for Aquanaut Motors to improve profits would be to obtain more sales. This is not feasible based on existing market conditions. The other choice that Aquanaut has is to reduce costs by closing one of the two facilities. There are two major issues with the capacity utilization rate at the Shark Plant, the limited capacity of line S2 to meet demand requirements for product B and the reduced demand of product A. First, Line S2's limited capacity will cause overspending for additional people and lead to overtime and extended workweeks. This will force Aquanaut to make an investment to expand capacity. The second issue is the lower demand for the A product. This will reduce the capacity utilization rate, forcing Aquanaut to maintain a costly infrastructure to produce the product. This will result in a waste of resources. In addition, the capacity of line D1 to produce product $\mathrm{C}$ is decreasing due to a reduction of demand in the market and an increasing number of competitors. Clearly Aquanaut faces continuing losses of revenue and increasing costs in its present situation. Its goal is analyze and select a plan that can most effectively reduce costs and improve profits.

\section{METHODOLOGY}

Aquanaut's ultimate goal was to achieve a reduction in cost of conversion. To reduce the capacity and cost required a detailed analysis of each facility's current and future capacity. Included in that study was the selection criteria for the best facility and the capital, expenses and time required to implement each possible option. The proposed reduction in capacity uses a cost model, which was created to determine the best alternatives for merging manufacturing processes. The cost model separated people, non-people, and fixed costs by facility, product line and product. During the analysis, the people costs were kept with the facility, the non-people costs resided with the product and fixed costs remained unchanged for simulation purposes. The model was developed by listing the feasible alternatives and comparing them with the 'do nothing' alternative using net present value and cash flow analysis. 
The following options were developed to understand the total cost of conversion. Option 1 served as a reference for comparison versus Options 2, 3 and 4:

- $\quad$ Option 1: Do nothing.

- $\quad$ Option 2: Manufacture all the motors in S1 product line.

- $\quad$ Option 3: Manufacture all the motors on S1 and S2 product lines.

- $\quad$ Option 4: Manufacture all the motors in D1 product line.

Options were generated based on the probability of consolidating each of the existing lines (D1, S1 \& S2). The option to assemble more than one motor on line S2 was considered but earlier discarded because it required an important level of capital and expense for machinery and plant expansion which Aquanaut could not afford. The level of resources was defined for each option. The information included the following data: capital and expense to implement the process change, implementation time, required modification of existing systems to accommodate the change and the assets to be released from production.

Table IV

Information On Resources, Expenses And Implementation Time For The Various Capacity Options

\begin{tabular}{|l|c|c|c|c|}
\hline Options & $\begin{array}{c}\text { Capital required in } \\
\text { millions of dollars }\end{array}$ & $\begin{array}{c}\text { Expenses projected in } \\
\text { millions of dollars }\end{array}$ & $\begin{array}{c}\text { Write-offs in millions } \\
\text { of dollars }\end{array}$ & Implementation time \\
\hline Do nothing & 8.0 & 2.0 & 0.0 & 6 months \\
\hline $\begin{array}{l}\text { Manufacture all motors in } \\
\text { S1 product line }\end{array}$ & 10.0 & 4.0 & 14.0 & 6 months \\
\hline $\begin{array}{l}\text { Manufacture all motors in } \\
\text { S1 and S2 product lines }\end{array}$ & 3.5 & 4.0 & 17.0 & 6 months \\
\hline $\begin{array}{l}\text { Manufacture all motors in } \\
\text { D1 product line }\end{array}$ & 8.0 & 4.0 & 27.0 & 6 months \\
\hline
\end{tabular}

A facility location analysis determined the final plant location using operational methods to assess strengths and weaknesses. The evaluation covered such factors as: quality of the product, on-time delivery, product cost, inventory turns, productivity, labor availability, labor cost, taxes, safety incidents, transportation costs, customer lead-time and work environment. The ratings of these factors are provided in Table $\mathrm{V}$.

Table V

Factor Rating For The Various Aquanaut Capacity Options

\begin{tabular}{|c|c|c|c|c|c|c|c|c|c|c|c|c|c|}
\hline 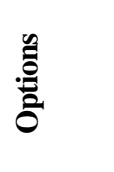 & 氞 & $\frac{\overrightarrow{0}}{:}$ & $\overrightarrow{8}$ & 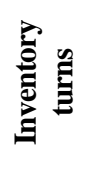 & 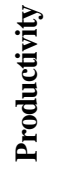 & 突 & 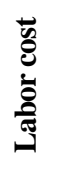 & 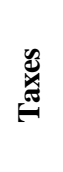 & 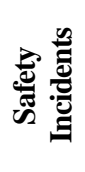 & 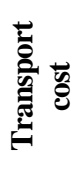 & 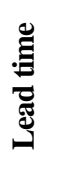 & 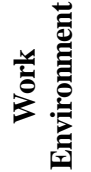 & हैं \\
\hline Option1 & 0 & 0 & 0 & 0 & 0 & 0 & 0 & 0 & 0 & 0 & 0 & 0 & 0 \\
\hline Option2 & 1 & 1 & 0 & 3 & 1 & 0 & 3 & 0 & 1 & 3 & 3 & 1 & 133 \\
\hline Option3 & 0 & 0 & 0 & 1 & 0 & 0 & 1 & 0 & 1 & 3 & 3 & 1 & 76 \\
\hline Option4 & 9 & 9 & 9 & 1 & 9 & 9 & 1 & 3 & 0 & 0 & 0 & 9 & 453 \\
\hline
\end{tabular}

A work content study was launched for each option to determine the line capacity by station. This study also evaluated the labor content and the effect of multiple products in one line. The study based its simulation of product costs on transferring the volume to the receiving plant at line level and maintaining a constant for non-people costs and fixed expenses. After the calculation of the new product costs, the new capital and expenses were added to each of the options for the final financial calculation. The new cost structure for each of the options was used to prepare a net income statement to calculate 
Return on Sales and a balance sheet to calculate assets and Return on Assets. A Net Present Value and Cash Flow Analyses were developed for each of the options to compare against the Option 1, "Do nothing."

After the analysis was finalized and the best option was selected, the concepts of modular manufacturing and outsourcing were applied to try to improve the cost of conversion. This showed that an improvement in the cost of conversion could be achieved by reducing the process time for the motor assembly and the cost of labor. The analysis of modular manufacturing departed from a labor content analysis at line station level in the evaluation of major elements of subassemblies of the motors. The labor content of the assembly of small components to the major elements of the motor was calculated and reviewed with suppliers that had been selected to assume the responsibility for this work. The objective of outsourcing the sub-assemblies was to receive a reduced number of components that would make the motor assembly process faster, reducing the complexity of the assembly line and the cost of labor. The analysis was done by calculating the work content before and after it was moved to suppliers. The labor savings were added to the financial model to quantify the benefits.

The analysis of outsourcing was necessary to reduce the complexity of multiple motor models on the same line and reduce the number of components handled in the same space. The concept behind this decision was to move low volume models to external suppliers and prevent slowdowns on the line that cause a loss of productivity. The desired cost reduction for producing these motors can be achieved by reducing the cost structure to support a low volume motor assembly, reducing the cost of labor by selecting a supplier with lower cost structure and increasing productivity in the Aquanaut assembly process.

\section{RESULTS AND DISCUSSION}

An analysis of the four options helped provide a clearer overview of the total cost of conversion. The analysis included: capital, expense, write-off, timing, capacity utilization rate, cost of conversion, return on sales, profit (loss), returnon-assets, net present value and cash flow versus Option 1. The results of the financial analysis of the various options are presented in Table VI.

Table VI

Financial Analysis Of Aquanaut Motors Capacity Options

\begin{tabular}{|l|c|c|c|c|c|c|c|c|}
\hline \multirow{2}{*}{ Options } & & $\begin{array}{c}\text { Cost of } \\
\text { Conversion }\end{array}$ & $\begin{array}{c}\text { Cash } \\
\text { Flow }\end{array}$ & NPV & ROS & $\begin{array}{c}\text { PBT in } \\
\text { Millions } \\
\text { of \$ }\end{array}$ & Assets & ROA \\
\hline \multirow{2}{*}{ Manufacture all in S1 } & With S1 & $\$ 334$ & $(64.0)$ & $(46.7)$ & $3 \%$ & 34 & 296 & $11 \%$ \\
\cline { 2 - 10 } & Without S1 & 336 & $(57.54)$ & $(42.2)$ & $3 \%$ & 30 & 257 & $12 \%$ \\
\hline \multirow{2}{*}{ Manufacture all in S1 and S2 } & With S1 & 319 & $(51.9)$ & $(39.0)$ & $4 \%$ & 40 & 311 & $13 \%$ \\
\cline { 2 - 10 } & Without S1 & 320 & $(64.3)$ & $(47.4)$ & $4 \%$ & 35 & 274 & $13 \%$ \\
\hline \multirow{2}{*}{ Manufacture all in D1 } & With S1 & 229 & 57.9 & 34.8 & $7 \%$ & 73 & 302 & $24 \%$ \\
\cline { 2 - 10 } & Without S1 & 230 & 59.1 & 36.2 & $7 \%$ & 67 & 265 & $25 \%$ \\
\hline \multirow{2}{*}{ Do Nothing } & With S1 & 291 & 0.0 & 0.0 & $5 \%$ & 52 & 323 & $16 \%$ \\
\hline $\begin{array}{l}\text { Manufacture all in D1 with Modular } \\
\text { manufacturing and outsourcing }\end{array}$ & Without S1 & 294 & 0.0 & 0.0 & $5 \%$ & 46 & 284 & $16 \%$ \\
\hline
\end{tabular}

The completed facility analysis showed that by consolidating at the Dolphin Plant, the quality, delivery and productivity would get better and turns, transportation and safety would get slightly worse. The cost of transportation was a factor that required a review between the options. The review identified a negative impact of two hundred thousand dollars if the Dolphin option was selected. The amount was considered in the financial analysis. (See table on next page) A closer look into the technology, capacity and flexibility of the Dolphin Plant assembly process made the option to consolidate there very attractive. 


\section{Option 1: Do nothing}

The option of doing nothing and maintaining the two plants would require an investment of 10 million dollars for capital and expenses to be able to continue producing the required motors after 2004 because of the reduced capacity of the S2 line. The total capacity would remain at 6,860 units per day with a demand of 1,495 per day and a capacity utilization rate of 22 percent. It would take approximately 12 months to install the additional capacity in line S2. The assets to be written-off would be zero dollars and would increase to four million dollars if product A was not produced outside of the company. The cost per unit would change from $\$ 287$ to $\$ 291$ and $\$ 294$ without product A. The profit before taxes would be 52 million dollars or 5.0 percent return on sales. The assets required by the business would be 323 million dollars or 16.0 percent of return on assets. The outsourcing of product A would change the financials to a profit before taxes of 46 million or 4.7 percent return on sales, with assets of 284 million dollars or 16.3 percent return on assets. The issues that remain in this option are the continued duplication of resources to produce similar products and the additional investment of 10 million collars to be able to produce the increased demand of product B.

\section{Option 2: Manufacture All The Motors In S1 Product Line}

The option of consolidating all motors at the Shark Plant's S1 line would require an investment of 12 million dollars for capital and expenses. The capacity would change to 2,660 units per day with a demand of 1,495 per day and a capacity utilization rate of 56 percent. It would take approximately 3 months to move the capacity to line S2. The assets that could be written-off would be 27 million dollars; this would increase to 31 million dollars if product A was not produced anymore. The cost per unit would change from $\$ 291$ in Option 1 to $\$ 334$ and $\$ 336$ without product S1. The Profit before tax would change from 52 million dollars or 5.0 percent return on sales in Option 1 to 34 million dollars or 3.3 percent of return on sales. The assets required by the business would decrease from 323 million dollars or 16.0 percent of return on assets to 296 million dollars or 11.6 percent of return on assets. The outsourcing of product S1 would change the financials to a profit before taxes of 30 million dollars or 3.0 percent return on sales, and assets of 257 million dollars or 11.6 percent return on assets. Comparing these figures against those of Option 1 shows that the five-year Net Present Value would be negative by 46.7 million dollars with an accumulated negative Cash Flow of 64.0 million dollars. The outsourcing of product S1 would change the five-year Net Present Value to a negative 42.2 million dollars with an accumulated negative Cash Flow of 57.7 million dollars. The issues that remain in considering this option are the continued problems with quality and productivity because S1 is the oldest assembly line of Aquanaut. This option would require a substantial investment in the line in the near future to upgrade it to the latest technology. The cost of people causes this option to be unfavorable versus the current Option 1. A comparison of the project results of the Net Present Value and Cash flow analyses between Options 1 and 2 for the years 2003 to 2007 are presented in Table VII.

\section{Option 3: Manufacture All Motors In S1 \& S2 Product Lines}

The option to consolidate at the Shark Plant and manufacture A \& C products in the S1 line and maintain the product B in the S2 line would require an investment of 14 million dollars for capital and expenses. The capacity would change to 3,780 units per day with a demand of 1,495 per day and a capacity utilization rate of 40 percent. It would take approximately 3 months to move the capacity to line S1. The assets that could be written-off would be 14 million dollars and 16 million dollars if product A was not produced anymore.

The cost per unit would change from \$ 291 in Option 1 to $\$ 319$ and $\$ 320$ without the $\$ 1$ product. The profit before tax would change from 52 million dollars or 5.0 percent return on sales in Option 1 to 40 million dollars or 3.9 percent of return on sales. The assets required by the business would change from 323 million dollars or 16.0 percent of return on assets to 311 million dollars or 12.9 percent of return on assets. The outsourcing of product S1 would change the financials to a profit before taxes of 35 million dollars or 3.5 percent return on sales and assets of 274 million dollars or 12.8 percent return on assets. When comparing this option against Option 1, the five-year Net Present Value is negative by 39.0 million dollars with an accumulated negative Cash Flow of 51.9 million dollars. The outsourcing of product A would change the five-year Net Present Value to a negative 64.3 million dollars with an accumulated negative Cash Flow of 47.4 million dollars. The issues that would remain as a result of choosing Option 3 would be continued problems with quality and productivity. S1 is the oldest assembly line of Aquanaut, and would require an additional investment in the near future to bring it in line with the latest technology. The S2 line would require additional resources to cover the increased demand of this product. The outcome 
would be an expansion of capacity or the need to operate 24 hours and 6 days per week. The cost of people would make this option an unfavorable one compared to Option 1. A comparison of the project results of the Net Present Value and Cash flow analyses between Options 1 and 3 for the years 2003 to 2007 are presented in Table VIII.

Table VII

Comparison Of The Projected Results Of Financial Analysis Between Options 1 And 2 (In Millions Of \$)

\begin{tabular}{|c|c|c|c|c|c|}
\hline Years & 2003 & 2004 & 2005 & 2006 & 2007 \\
\hline People costs & $\$(18.4)$ & $\$(18.4)$ & $\$(18.4)$ & $\$(18.4)$ & $\$(18.4)$ \\
\hline \multicolumn{6}{|c|}{ Non-people Costs Operating Utilities Freight } \\
\hline & 0.0 & 0.0 & 0.0 & 0.0 & 0.0 \\
\hline & 0.0 & 0.0 & 0.0 & 0.0 & 0.0 \\
\hline & 0.3 & 0.3 & 0.3 & 0.3 & 0.3 \\
\hline \multicolumn{6}{|l|}{ Other } \\
\hline Normal depreciation/Rent & 1.4 & 1.4 & 1.4 & 1.4 & 1.4 \\
\hline Taxes/Insurance & 0.0 & 0.0 & 0.0 & 0.0 & 0.0 \\
\hline Write-offs & $(27.0)$ & & & & \\
\hline Move costs & $(2.0)$ & & & & \\
\hline Other Expenses: Relocation & $(2.0)$ & & & & \\
\hline PBIT & $(47.70)$ & $(16.70)$ & $(16.70)$ & $(16.70)$ & $(16.70)$ \\
\hline Tax effect $38 \%$ & 18.1 & 6.3 & 6.3 & 6.3 & 6.3 \\
\hline Add: Depreciation/Non-Cash & 1.4 & 1.4 & 1.4 & 1.4 & 1.4 \\
\hline Less: Capital & 0.0 & & & & \\
\hline Net Cash Flow & $(28.2)$ & $(9.0)$ & $(9.0)$ & $(9.0)$ & $(9.0)$ \\
\hline Cumulative Cash Flow & $(28.2)$ & $(37.1)$ & $(46.1)$ & $(55.0)$ & $(64.0)$ \\
\hline NPV@15\% & $(46.7)$ & & & & \\
\hline
\end{tabular}

Table VIII

Comparison Of The Projected Results Of Financial Analysis Between Options 1 And 3 (In Millions Of \$)

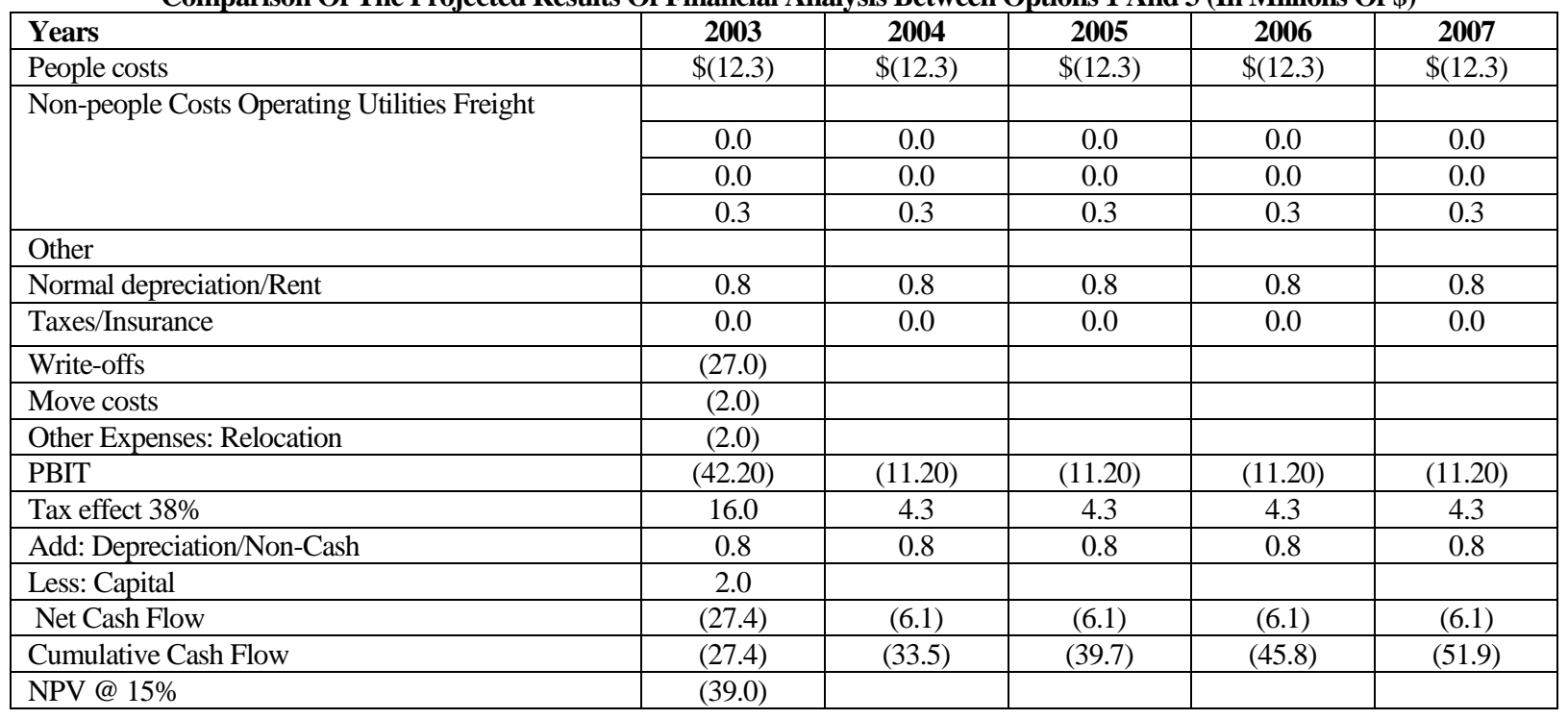




\section{Option 4: Manufacture All Motors In D1 Product Line}

The option to consolidate at the Dolphin Plant and manufacture all the motors in the D1 line would require an investment of 7.5 million dollars for capital and expenses. The capacity would change to 3,080 units per day with a demand of 1,495 per day and a capacity utilization rate of 49 percent. It would take approximately 3 months to move the capacity to the D1 line. The assets to be written-off would be 17 million dollars and 19 million dollars if product A was not produced anymore. The cost per unit would change from $\$ 291$ in Option 1 to $\$ 229$ and $\$ 230$ without product A. The Profit before tax would change from 52 million dollars or 5.0 percent return on sales in Option 1 to 73 million dollars or 7.1 percent of return on sales in Option 4. The assets required by the business would change from 323 million dollars or 16.0 percent of return on assets to 302 million dollars or 24.3 percent of return on assets. The outsourcing of product A would change the financials to a profit before taxes of 67 million dollars or 6.8 percent return on sales and assets of 265 million dollars or 25.4 percent return on assets. When comparing this option against Option 1, the five-year Net Present Value would be positive by 34.8 million dollars with an accumulated positive Cash Flow of 57.9 million dollars. The outsourcing of product A would change the fiveyear Net Present Value to a positive 36.2 million dollars with an accumulated negative Cash Flow of 59.1 million dollars. The issue that would remain by choosing this option is the increased cost of transportation for the business. The effect of transportation costs is included in the financials but the lead-time to customers would increase by two days. The cost of people for this option causes it to be more favorable than Option 1. Option 4 was selected for implementation by Aquanaut based on the information available and the analysis performed. A comparison of the project results of the Net Present Value and Cash flow analyses between Options 1 and 4 for the years 2003 to 2007 are presented in Table IX.

Table IX

Comparison Of The Projected Results Of Financial Analysis Between Options 1 And 4 (In Millions Of \$)

\begin{tabular}{|l|c|c|c|c|c|}
\hline Years & $\mathbf{2 0 0 3}$ & $\mathbf{2 0 0 4}$ & $\mathbf{2 0 0 5}$ & $\mathbf{2 0 0 6}$ & $\mathbf{2 0 0 7}$ \\
\hline People costs & $\$ 21.2$ & $\$ 21.2$ & $\$ 21.2$ & $\$ 21.2$ & $\$ 21.2$ \\
\hline Non-people Costs Operating Utilities Freight & & & & & \\
& & & & & \\
& 0.0 & 0.0 & 0.0 & 0.0 & 0.0 \\
\cline { 2 - 6 } & 0.0 & 0.0 & 0.0 & 0.0 & 0.0 \\
\cline { 2 - 6 } & $(0.5)$ & $(0.5)$ & $(0.5)$ & $(0.5)$ & $(0.5)$ \\
\hline Other & & & & & \\
\hline Normal depreciation/Rent & 1.7 & 1.7 & 1.7 & 1.7 & 1.7 \\
\hline Taxes/Insurance & 0.0 & 0.0 & 0.0 & 0.0 & 0.0 \\
\hline Write-offs & $(17.0)$ & & & & \\
\hline Move costs & $(4.5)$ & & & & \\
\hline Other Expenses: Relocation & $(2.0)$ & & & & \\
\hline PBIT & $(1.10)$ & 22.40 & 22.40 & 22.40 & 22.40 \\
\hline Tax effect 38\% & 0.4 & $(8.5)$ & $(8.5)$ & $(8.5)$ & $(8.5)$ \\
\hline Add: Depreciation/Non-Cash & 1.7 & 1.7 & 1.7 & 1.7 & 1.7 \\
\hline Less: Capital & $(5.5)$ & & & & \\
\hline Net Cash Flow & $(4.5)$ & 15.6 & 15.6 & 15.6 & 15.6 \\
\hline Cumulative Cash Flow & $(4.5)$ & 11.1 & 26.7 & 42.3 & 57.9 \\
\hline NPV @ 15\% & 34.8 & & & & \\
\hline
\end{tabular}

\section{Modular Manufacturing \& Outsourcing - Improvement}

Option 4 was selected to manufacture all the motors at the Dolphin plant. With that selection came the recommendation to apply Modular Manufacturing and Outsourcing concepts for further improvements. Modular manufacturing would make the assembly process faster and simpler by reducing the number of components to assemble and line density. The outsourcing of the S1 product would reduce the number of components and the number of dedicated workstations needed to assemble low volume products. Next, the motor assembly process was analyzed using the concept of modular manufacturing. The analysis consisted of identifying high level sub-assemblies that could move to external suppliers. The benefits were calculated based on the amount of work content that could be moved with the sub-assemblies to the supply base. The analysis showed that labor could be reduced by $22 \%$ in product $\mathrm{B}$ and $18 \%$ in product $\mathrm{C}$. That reduction is the value 
of the labor savings, assuming a $\$ 20.00$ per hour cost for Aquanaut labor versus a $\$ 13.00$ per hour cost from Aquanaut's suppliers. Annual labor savings based on this reduction in hourly wages are in the range of 5.9 million dollars.

Aquanaut has the opportunity to outsource product A with Snapper, a company that already supplies Aquanaut with components and different types of motors. That action would reduce the cost of conversion by 2.3 million dollars and simplify the new assembly process for the Dolphin plant. The logical strategy would be to move low volume motors to this supplier and make Dolphin a leaner, simpler plant. The benefits of outsourcing total 2.3 million dollars for the Shark Plant and 0.5 million dollars for the Dolphin Plant. Outsourcing would reduce people costs by 45 percent and would decrease operating cost by 25 percent. However, the cost of transportation would increase by 50 percent because of transportation costs to this location. The results of financial analysis associated with the approach of modular manufacturing and outsourcing are presented in Table X.

Table X

Financial Analysis Of Modular Manufacturing And Outsourcing

\begin{tabular}{|l|c|c|c|}
\hline Product & A & B & C \\
\hline Before estimation - minutes & $\$ 128.57$ & $\$ 153.43$ & $\$ 87.43$ \\
\hline After estimation - minutes & 111.86 & 120.43 & 68.14 \\
\hline Total labor cost & 19.50 & 38.50 & 22.50 \\
\hline Supplier cost & 5.43 & 10.73 & 6.27 \\
& 4.07 & 8.04 & 4.70 \\
\hline Total costs & 9.51 & 18.77 & 10.97 \\
\hline Change in costs & 9.99 & 19.73 & 11.53 \\
\hline Volume & 11,760 & 244,000 & 115,000 \\
\hline Savings & $\$ 117,526.50$ & $\$ 4,814,425.00$ & $\$ 1,326,093.75$ \\
& & $6,140,518.75$ & $6,258,045.25$ \\
\hline
\end{tabular}

\section{Benefits Modular Manufacturing And Outsourcing}

The approach to consolidate operations at the Dolphin Plant to manufacture B \& C motors in D1 line, the outsourcing of product $\mathrm{A}$, and the implementation of modular manufacturing would require no investment compared to the original Option 4. These actions would change capacity to 3,160 units per day with a demand of 1,495 per day and a capacity utilization rate of 47 percent or 2 percent less than Option 4. The timing would be approximately three months to move the A product to Snapper, the external supplier, and six months to move the work content defined in the modular approach to the supplier base.

The cost per unit would remain the same as in the original Option 4 but profit before tax would increase from 67 million to 73 million dollars and return on sales would increase from 6.8 percent to 7.1 percent. The assets required by the business would change from 302 million dollars or 24.3 percent of return on assets to 298 million dollars or 24.3 percent of return on assets. When comparing this option against Option 4, the five-year Net Present Value would increase by 18.6 million dollars with an additional accumulated Cash Flow of 11.9 million dollars. Adding modular assembly to this option will reduce costs further. It will cut the process time for the motor assembly by handling fewer components and by simplifying the assembly line. The outsourcing of product A will ease the complexity of handling multiple motor models on the same line and decrease the number of components handled in the same space. The assembly process will decrease the level of density of work, thereby avoiding process slowdowns and loss of productivity. By outsourcing, cost reduction will be achieved by eliminating the cost associated with the support of low volume motors and reducing the cost of labor. Producing the product with an overseas supplier with lower cost structure will also contribute to cost reduction. A comparison of the project results of the Net Present Value and Cash flow analyses between Option 1 and Option 4, modified with the addition of modular manufacturing and outsourcing, for the years 2003 to 2007 are presented in Table XI. 
Table XI

Comparison Of The Results Of Financial Analysis (In Millions Of \$) Between Options 1 And The Modified Option 4

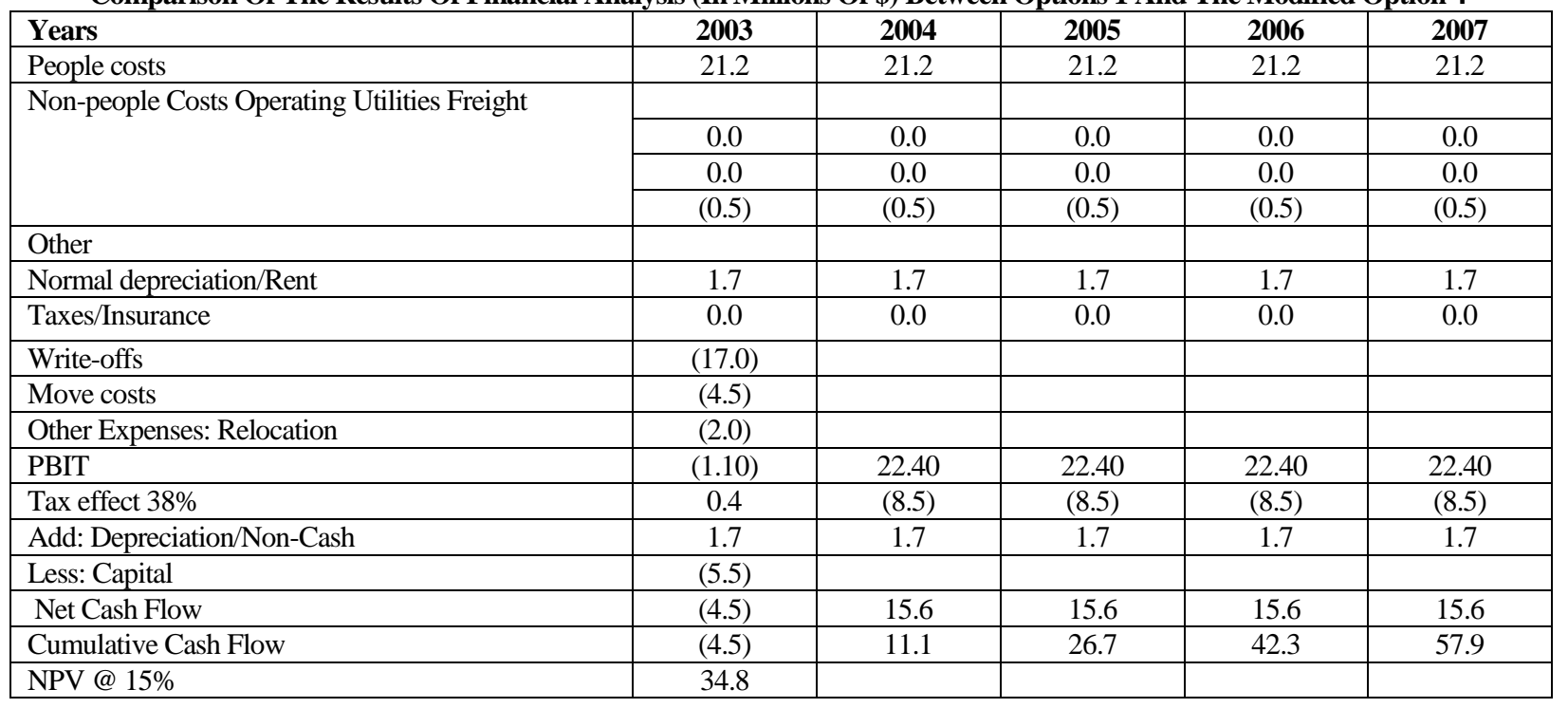

\section{CONCLUSIONS}

Many factors influence the decision to expand manufacturing capacity, but a weak connection between capacity management and the business strategy causes multiple, duplicated facility investments. The result is heavy cost structures. A recommended approach when capacity duplications exist is to evaluate the product costs by using the cost model described in this paper and determine the best alternatives to merge manufacturing processes. The cost model works by separating people, non-people, and fixed costs by facility, product line and product. The model recommends that businesses keep their people costs associated with the facility costs, maintain the non-people costs with the product, and maintain the fixed costs constant. After any analysis, it is necessary for a company to add or remove additional costs to reflect changes in the operations flow. Net present value and cash flow are the most useful tools for a company to use to determine the best alternatives.

It is also important to keep in mind that implementing a decision process model to expand or reduce capacity requires a good understanding of the eight critical categories for strategic manufacturing: capacity, facilities, technology, vertical integration, work force, quality, production control and the development of the organization. Modular manufacturing reduces production costs by allocating work to those factories that have lower labor costs (Welch, 2001). It also reduces the complexity of processes by decreasing the number of components and the complexity of manufacturing processes. Applying the concept helps to increase a business's existing capacity and reduce its labor costs by moving work content to external suppliers. Outsourcing is a valuable tool to reduce the complexity of manufacturing processes by reducing the number of components and dedicated operations, especially when obsolete or low demand product can be moved to suppliers. Modular manufacturing and outsourcing helps manufacturing processes run leaner operations by increasing speed, lowering process time, and maximizing capacity utilization. A defined strategy to outsource low volume products in order to simplify core business is valuable and recommended.

\section{REFERENCES}

1. Butler, M.P. (1990), Facility and Capacity Planning Using Sales forecasting Today's Industrial Engineer, Industrial engineering, Vol. 22 No.6, pp. 52-55.

2. Marucheck, A. and McClelland, M. (1992) Planning Capacity Utilization in an Assemble-to-order Environment, International Journal of Operations and Production Management, Vol.12 No. 9, pp. 18-38. 
3. Olhager, J., Rudberg, M., and Wilkner, J., (2001), Long-term capacity management: Linking the perspectives from manufacturing strategy and sales and operations planning, International Journal of Production Economics, Vol. 69, pp. 215-225.

4. Reeve, J., (2001), Strategic Facility Planning improves Capital Decision Making, Integrated Delivery Systems, Healthcare Financial Management, Vol. 55 No.3, pp. 35-38.

5. Silva, D., (1994), Capacity Management: Get the level of detail right, Hospital Material Management Quarterly, Vol. 15 No. 4, pp. 67-74.

6. Skinner, W., (1969), Manufacturing: Missing link in Corporate Strategy, Harvard Business Review, Vol. 47 No. 3, 1969, pp. $136-145$.

7. $\quad$ Strozniak, P. (2001) Outsourcing boom, Industry Week, Vol. 250 No. 4, pp11-12.

8. Velocci, Jr. A. (2001), Contracting out, Aviation Week \& Space Technology, 10/15/01, Vol. 155 No.16, p70, 2p, 2c http://search.epnet.com/direct.asp?an $=2423402 \& \mathrm{db}=$ buh.

9. Orr, S. (1999), The role of capacity management in Manufacturing Strategy: Experiences from the Australian Wine Industry, Technology Analysis \& Strategic Management, Vol. 11 No. 1, pp. 45 - 53.

10. Welch, D. (2001), Why Detroit is going to pieces: Modular outsourcing is gaining converts-even among unions, Business Week, 3747, p 76B. 